特集 血行再建術 1:CEA

原 著

CAS 導入後の CEA 治療成績

西尾 雅実, 矢野 喜寛, 高野 浩司, 江村 拓人

\title{
Clinical Results of Carotid Endarterectomy after Introducing Carotid Artery Stenting to Our Hospital
}

\author{
Masami Nishio, M.D., Yoshihiro Yano, M.D., Kouji Takano, M.D., and Takuto Emura, M.D. \\ Department of Neurosurgery, Toyonaka Municipal Hospital, Toyonaka, Osaka, Japan
}

\begin{abstract}
Summary: Carotid endarterectomy (CEA) is a standard method to prevent stroke in patients with carotid artery stenosis. Carotid artery stenting (CAS) is a newly developed alternative method that we brought to our hospital in 2013. We selected CEA or CAS based on the procedure-related risks specific to each case. High-risk patients, such as those with vulnerable plaque, were more often treated with CEA, which may have influenced the outcomes. This study revealed the clinical results of CEA after introducing CAS.

Retrospectively collected data for 26 patients each of CEA and CAS performed in our hospital from April 2013 to March 2016 were analyzed. CEA was performed in 22 men and 4 women aged 36-82 years (mean, $66.9 \pm 12.9$ years). Stenosis rate was 40-99\% (mean, $74.9 \pm 19.9 \%$ ). Twenty-two patients underwent CEA because of plaque morphologies, including vulnerable plaque, long plaque, mobile plaque, hematoma in and around the plaque, and heavily calcified plaque. Postoperative complications occurred as follows: transient hemiparalysis in 1 patient, transient hoarseness in 1 patient, pneumonia in 2 patients, and heart failure in 1 patient. No permanent morbidities were recognized. In 3 patients, spotty diffusion-weighted images of high-intensity signal lesions were obtained on post-operative magnetic resonance imaging.

Even after adopting CAS in our hospital, CEA was performed with low and acceptable complication rates.
\end{abstract}

\section{Key words: \\ - carotid endarterectomy \\ - carotid artery stenting \\ - operative complication}

Surg Cereb Stroke (Jpn) 46: 411-415, 2018

\section{はじめに}

脳卒中ガイドライン 2015 では頝部頚動脈狭窄症の血行 再建術として, 内膜剥離術 (carotid endarterectomy：CEA) が標準治療と位置づけられており, 頚動脈ステント留置術 (carotid artery stenting : CAS) は代替治療として CEA 高 危険群に行ってもよいと記載されている ${ }^{13)}$. しかし, 低侵 襲治療への需要は高く, 日本ではCAS も広く行われるよ
うになっている. 当院ではCEA のみを行ってきたが, 2013 年にCAS を導入した. CAS 導入により CEA の治療 成績が影響されている可能性があると思われた。 そこ で, CAS 導入後の CEA の治療成績について後方視的に検 討した。

対象と方法

2013 年 4 月から 2016 年 3 月の間に当施設にて䅡部䅡動

市立豊中病院 脳神経外科(受稿日 2017. 8. 14) (脱稿日 2017. 12. 12)〔連絡先：干 560-8565 大阪府豊中市柴原町 4-14-1 市立豊中病院 脳 神経外科 西尾雅実] [Address correspondence: Masami NisHIO, M.D., Department of Neurosurgery, Toyonaka Municipal Hospital, 4-141 Shibahara-cho, Toyonaka, Osaka 560-8565, Japan] 
脈狭窄症に対して血行再建 (CEA，CAS)を行った 52 例の うち CEA を行った 26 側 26 例を対象とした。 同時期に, CAS は 26 側 26 例に行われていた，血行再建を行う基準 はNASCET 狭窄度を用い，基本的に症候性病変では $50 \%$ 狭窄以上，無症候性病変では $80 \%$ 狭窄以上とした。

CEA またはCAS の選択にあたって, 脳 MRI・MR angiography, 頚動脈エコー, CT angiography, MRI-black blood (BB) 法, カテーテル血管撮影, single photon emission computed tomography (SPECT)を行い, 血管性状, アクセスルート, プラーク性状(長さ, 不安定性, 石灰化, 血栓付着, プラークの可動性)の評価を行った。また，全 例に心臓エコー, 冠動脈 CTA またはカテーテル冠動脈撮 影による評価を行った。治療方法は, 脳神経外科・神経内 科合同カンファレンスで決定した。基本的に T1BB 法で のプラーク輝度が胸鎖乳突筋比で 1.5 を超えるもの, プ ラークが長いもの, プラーク周囲血栓, 可動性プラーク, 高度石灰化プラーク，アクセスルートの屈曲蛇行が強いも のは CEA を選択した，対側䅡動脈閉塞， $\mathrm{C} 2$ 椎体中位を 超える高位病変, CEA 後再狭窄, 澒部放射線治療後, 心 不全など全身麻酔の危険性が高いものはCASを選択し た. 同程度の安全性と判断した場合には, 患者希望を勘案 して決定した. 冠動脈評価にて冠動脈血行再建が必要と判 断された場合には頚動脈血行再建に先行して行った.

CEA は全身麻酔下に, 経口気管内择管を行い, somatosensory evoked potentials (SEP)を術中モニタリングとし て用いた，術前服用していた抗血小板薬は継続し，血流遮 断前にヘパリン全身投与, activated clotting time(ACT) 230 前後となるようにコントロールした. 全例で内シャン ト(古井式バイバルーンシャント)を使用した，パッチグラ フトは使用しなかった. CAS は, 局所麻酔下に遠位塞栓 防止機器を使用して行った。術前より抗血小板薬 2 剂内服 を行い，全身へパリン化し ACT 300 以上となるようにし た。使用機材は, 症例ごとに検討して選択した。

CEA 症例について, 患者背景, 症候性の有無, 狭窄 度, 治療の時期, 使用抗血小板薬, CEA 選択の理由, 周 術期合併症の検討を行った。また，同時期に行われた CAS 症例についても同様の検討を行い比較した。過灌流 は, 術後 1-2 日目の SPECT で, 患側血流が対側に比べて $20 \%$ 以上増加したものとした. 治療時期は, 脳虚血発作に よる入院に引き続き同一入院中に血行再建術を行ったもの を急性期治療とした，データは平均土標準偏差で示し た。統計処理は, Wilcoxon rank sum, Fisher's exact test を用い $\mathrm{p}<0.05$ を有意とした．本研究は市立豊中病院倫理 委員会の承認を得て行った(課題番号 2017-09-04).

\section{結果}

CEA が行われたのは男性 22 例 (84.6\%), 女性 4 例, 36-82 歳 (平均 $66.9 \pm 12.9$ 歳) であった。症候性病変 20 例 (76.9\%), 脳梗塞急性期治療 11 例 (42.3\%) に行われてい た。狭窄率は 40-99\% (平均 74.9 19.9\%) であった. 既往 歴は, 高血圧 16 例 (61.5\%), 糖尿病 7 例 (26.9\%), 脂質異 常症 13 例 (50\%), 契煙 5 例 (19.2\%) だった. percutaneous coronary intervention(PCI), coronary artery bypass grafting (CABG) 既往症例はなかった. 術前冠動脈評価に より冠動脈狭窄が発見され, 血行再建が 4 例 (15.4\%) に先 行して行われていた(PCI 3 例, CABG 1 例). 手術時に抗 血小板薬 2 郕内服していたのは 20 例 $(76.9 \%)$ であった.

同時期にCAS は男性 21 例 (80.8\%), 女性 5 例に施行さ れ, 55-85 歳 (72.8 歳 8.1 歳), 症候性病変 22 例 (84.6\%), 狭窄率 60-99\% (平均 79.9 $13.1 \%$ ) であった. 既往歴は高 血圧 17 例 (65.4\%), 糖尿病 13 例 (50\%), 脂質異常症 10 例 (38.5\%), 契煙 3 例 (11.5\%), PCI, CABG 6 例であった. 8 例 (30.8\%) で急性期治療が行われ, 冠動脈血行再建が先 行したのは 4 例 (PCI：15.4\%)であった. 抗血小板薬 2 郕 服用していたのは 26 例 (100\%)であった (Table 1).

CEA の選択理由は (重複あり), 不安定プラーク 14 例 (53.8\%), 長い病変 5 例 (19.2\%), 可動性プラーク・血栓 3 例 (11.5\%), 高度石灰化プラーク 2 例 $(7.7 \%)$, 患者希望 2 例 $(7.7 \%)$, 大動脈弁狭窄 1 例 $(3.8 \%)$, 造影剂アレル ギー 1 例 ( $3.8 \%)$ であった. 重複を除くとプラーク性状が 選択理由であったものは 21 例 (80.8\%)であった（Table 2).

CAS の選択理由は患者希望 14 例 (53.8\%), 慢性心不全 5 例 $(19.2 \%)$, 高位病変 2 例 $(7.7 \%)$, 放射線治療後 2 例 $(7.7 \%)$, 対側䅡動脈閉塞 2 例 $(7.7 \%), \mathrm{CEA}$ 後再狭窄 1 例 (3.8\%)であった (Table 3).

T1BB 法でのプラークと胸鎖乳突筋の輝度比は, CEA 群 で $1.93 \pm 0.75$, CAS 群で $1.35 \pm 0.26$ ( $\mathrm{p}=0.001$ ) であった. CEA 群のうち不安定プラークが選択理由であった 14 例では 2.43 土0.62であった. プラーク長は CEA 群で $17.8 \pm 6.7 \mathrm{~mm}$, CAS 群で $11.2 \pm 3.8 \mathrm{~mm}(\mathrm{p}=0.0002)$ であった (Table 4).

CEA の周術期合併症としては一過性片麻痺 1 例 (3.8\%), 一過性嗄声 3 例 (11.5\%), 肺炎 2 例 (7.7\%), 心不全 1 例 (3.8\%)を認めた，退院時に残存するものはなかった，術 後 MRI では DWI 高信号を 3 例 $(11.5 \%)$ に認めた。過灌流 を 1 例に認めたが, 症候性となったものはなかった. 周術 期の症候性心筋虚血発症はなかった。

CAS の周術期合併症は一過性片麻瘦 1 例 (3.8\%), 心不全 1 例 (3.8\%)を認めた。過灌流を 1 例 (3.8\%), 術後 MRI DWI 高信号を 6 例 $(23.1 \%)$ に認めた。症候性心筋虚血発症例は 認めなかった (Table 5). 
Table 1 Demographic characteristics of patients who underwent carotid artery revascularization

\begin{tabular}{llll}
\hline & CEA (26 cases) & CAS (26 cases) & p value \\
\hline Age & $66.9 \pm 12.9$ & $72.8 \pm 8.1$ & 0.083 \\
Male: Female & $22: 4$ & $21: 5$ & 1 \\
Symptomatic stenosis & $20(76.9 \%)$ & $22(84.6 \%)$ & 0.726 \\
Stenotic rate (\%) & $40-99(74.9 \pm 19.9)$ & $60-99(79.9 \pm 13.1)$ & 0.234 \\
Past history & & & \\
$\quad$ Hypertension & $16(61.5 \%)$ & $17(65.4 \%)$ & 1 \\
$\quad$ Diabetes mellitus & $7(26.9 \%)$ & $13(50.0 \%)$ & 0.153 \\
$\quad$ Dyslipidemia & $13(50 \%)$ & $10(38.5 \%)$ & 0.577 \\
$\quad$ Current smoking & $5(19.2 \%)$ & $3(11.5 \%)$ & 0.703 \\
$\quad$ Coronary artery disease & 0 & $6(23.1 \%)$ & $0.0226^{*}$ \\
Acute phase CEA/CAS & $11(42.3 \%)$ & $8(30.8 \%)$ & 0.565 \\
PCl/CABG ahead of CEA/CAS & $4(15.4 \%)$ & $4(15.4 \%)$ & 1 \\
Double antiplatelet therapy & $20(76.9 \%)$ & $26(100 \%)$ & $0.0226^{*}$ \\
\hline
\end{tabular}

CEA: carotid endarterectomy, CAS: carotid artery stenting, $\mathrm{PCl}$ : percutaneous coronary intervention, CABG: coronary artery bypass grafting, * $: p<0.05$

Table 2 Reasons to choose carotid endarterectomy as the revascularization method

\begin{tabular}{ll}
\hline & Number of cases (\%) \\
\hline Vulnerable plaque & $14(53.8 \%)$ \\
Long lesion & $5(19.2 \%)$ \\
$\begin{array}{l}\text { Mobile plaque, hematoma around } \\
\text { plaque }\end{array}$ & $3(11.5 \%)$ \\
Highly calcified plaque & $2(7.7 \%)$ \\
Patients' preference & $2(7.7 \%)$ \\
Aortic valve stenosis & $1(3.8 \%)$ \\
Contrast enhancement allergy & $1(3.8 \%)$ \\
\hline
\end{tabular}

Table 3 Reasons to choose carotid artery stenting as the revascularization method

\begin{tabular}{ll}
\hline & Number of cases $(\%)$ \\
\hline Patients' preference & $14(53.8 \%)$ \\
Chronic heart failure & $5(19.2 \%)$ \\
High position plaque & $2(7.7 \%)$ \\
Post-cervical radiotherapy & $2(7.7 \%)$ \\
Contralateral carotid occlusion & $2(7.7 \%)$ \\
Restenosis after carotid endarter- & $1(3.8 \%)$ \\
ectomy & \\
\hline
\end{tabular}

Table 4 Plaque characteristics

\begin{tabular}{lllc}
\hline & CEA (26 cases) & CAS (26 cases) & $p$ \\
\hline Plaque/SCM ratio in T1BB & $1.93 \pm 0.75$ & $1.35 \pm 0.26$ & $0.001^{*}$ \\
$\begin{array}{l}\text { Maximum plaque length } \\
\text { (mm) }\end{array}$ & $17.8 \pm 6.7$ & $11.2 \pm 3.8$ & $0.0002^{*}$ \\
\hline
\end{tabular}

CEA: carotid endarterectomy, CAS: carotid artery stenting, SCM: sternocleidomastoid muscle, T1BB: black blood method in T1 weighted image, $*: p<0.05$

Table 5 Incidence of clinical events

\begin{tabular}{llll}
\hline & CEA (26 cases) & CAS (26 cases) & p \\
\hline DWI HI lesion & $3(11.5 \%)$ & $6(23.1 \%)$ & 0.465 \\
Hyperperfusion & $1(3.8 \%)$ & $1(3.8 \%)$ & 1 \\
Hemiparalysis (transient) & $1(3.8 \%)$ & $1(3.8 \%)$ & 1 \\
Hoarseness (transient) & $3(11.5 \%)$ & 0 & 0.235 \\
Heart failure & $1(3.8 \%)$ & $1(3.8 \%)$ & 1 \\
Pneumonia & $2(7.7 \%)$ & 0 & 0.490 \\
\hline
\end{tabular}

CEA: carotid endarterectomy, CAS: carotid artery stenting, DWI HI: diffusion weighted image high intensity 


\section{考察}

CEA と CAS の比較についてこれまで種々の RCT が行 われてきた. SAPPHIRE studyでは CEA 高危険群に対す るCASの非劣勢が証明された ${ }^{16)}$ 。その後に行われた $3 つ$ の RCT (SPACE，EVA-3S，ICSS)ではCAS の非劣勢は 証明されなかったが512)15), CAS 時の遠位塞栓防止機器の 使用が任意であるなどの問題点が指摘された。一方，遠位 塞栓防止機器の使用が義務づけられた CRESTでは, CEA と CAS は同等の成績であった²).

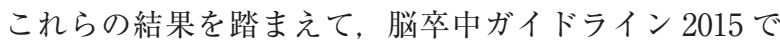
は CEA を標準治療とし, CEA 危険因子(心臟疾患, 重篤 な呼吸器疾患, 対側頚動脈閉塞, 対側喉頭神経麻瘦, 頚部 直達手術，頚部放射線治療の既往， CEA 再狭窄例）をもつ 症例にCAS が勧められている(グレード B)。CEA 危険因 子をもたない症例に対してはCASを考慮してもよいが, 十分な科学的根拠がない(グレード $\mathrm{C} 1)$ と記載されてい る。また, 高齢者, 著しい屈曲や石灰化を伴うなど動脈の 状態が血管内手術に好ましくない場合は, CEAの選択が 勧められている(グレード B)，無症候性病変については, 高度狭窄の場合にCEAの代替治療としてCASを考慮し てよい(グレード C1) となっている

AHA ガイドラインでは, 症候性高度狭乍で CEA の代 替として行ってもよい(Class IIa), 70 歳以上では CEA が 望ましく, 70 歳未満では周術期合併症と長期成績の両方 でCAS と CEA は同等である (Class IIa) と記載されてい $ろ^{8)}$.

CEA とCASの選択について, Noiphthak ${ }^{14)}$ はCEA 高危険因子として心疾患をはじめとした全身状態と, CEA 既往や放射線照射後など頚部の解剖学的状況を挙 げ，こうした群にはCASを考慮するとしている。また， CAS 高危険因子として, プラーク性状と血管の状態を挙 げ,これらをもつ患者には CEA を考慮し，どちらの危険 性ももつ群には最良の内科的治療を行い，治療法は症例ご とに検討することを提唱している．

本研究では, 症例ごとに適切と考えられる治療方法を選 択する方法で行ったが，CEA と CAS は同数で行われてい た．CEA を選択した理由としては，プラーク性状による ものが 21 例 (80.8\%) と多かった. T1BB 法でのプラークと 胸鎖乳突筋の輝度比では CEA 群で 1.93 と CAS 群 1.35 に 比し有意に高く、プラーク長は CEA 群で $17.8 \mathrm{~mm}$ と CAS 群 $11.2 \mathrm{~mm}$ に比し有意に長かった。また，大動脈弁 狭窄や，造影剂アレルギーなどによって選択されている症 例もあった。すなわち，CASの危険性が比較的高い症例 にCEA が選択されていたと考えられる。また，冠動脈血 行再建を行った患者は既往と術前検査での発見をあわせて
CEA 群で 4 例, CAS 群で 10 例であり, 全身麻酔の危険 性があると考えられる冠動脈病変患者は CEA で少ない傾 向がみられた，症例ごとに治療方法を適切に選択すること で, $\mathrm{CEA}$ のならず, $\mathrm{CEA} ・ \mathrm{CAS}$ 全体として䅡動脈血行 再建の合併症率を低く抑えることが可能であったと考えら れた。

CREST のサブ解析では高齢者で CAS の成績が悪く, AHA ガイドラインでは 70 歳以上は CEA が推奨されてい る ${ }^{8)}$. しかし, 本研究では CEA 群の平均は 66.9 歳で CAS 群の平均 72.8 歳より低い傾向がみられた。当院では年齢 を選択基準としていないこと, 高齢者では心不全など全身 麻酔のリスクが高い患者が増えることや，より低侵襲な治 療を希望する傾向にあること, などが要因として考えられ た。

澒動脈病変には冠動脈病変の合併が多いことが報告され ている. 頚動脈病変患者の $25-60 \%$ で冠動脈病変を認 $\bigotimes^{13)}$, 自覚症状のない心筋虚血は $20-40 \%$ にあるとの報告 があり ${ }^{4) 11}$, 冠動脈撮影で評価した結果, 冠動脈疾患既往 のない患者の $60.4 \%$ で有意狭窄があったとされている ${ }^{9}$. 冠動脈疾患が発見された場合, 心筋血行再建を先行して行 うことで周術期の心筋虚血発症を予防でき，良好な転帰に つながった ${ }^{67710)}$ と報告されている.

本研究では, CEA 術前に冠動脈疾患の既往がある患者 はなかったが, 冠動脈検查を行った結果, $15.4 \% て ゙$ 新規に 血行再建 $(\mathrm{CABG}, \mathrm{PCI})$ が必要な狭窄が発見された. 先行 して治療を行った結果, 周術期の心筋虚血発症は認めな かった. CAS 症例と合わせると, 52 例中 6 例にPCI, CABG の既往があり，術前検査で新規に 8 例 $/ 42$ 例 (19.0\%) で CABG, PCI が必要な狭窄が発見された。両方を合わせ ると, $14 / 52(26.9 \%)$ で血行再建の必要な冠動脈疾患が存 在していた，術前に積極的な冠動脈検查を行い，必要があ れば，先行して冠動脈血行再建を行うことで，周術期の冠 動脈虚血発症を予防することが可能であった。

\section{結 語}

CAS 導入後の CEA はプラークが不安定, 血栓付着, 高 度石灰化など，手術リスクの危険性が高い症例が多くみら れた，症例ごとに十分な術前検討を行うことでCAS を含 めた血行再建全体の合併症を低く抑えることが可能であっ た。

著者全員は, 日本脳神経外科学会への COI 自己申告を 完了しています。本論文の発表に関して, 開示すべき COI はありません。 


\section{文献}

1) Aronow WS, Ahn C, Schoenfeld MR, et al: Prognostic significance of silent myocardial ischemia in patients $>61$ years of age with extracranial or common carotid artery disease with and without previous myocardial infarction. Am J Cardiol 71: 115-117, 1993

2) Brott TG, Hobson RW 2nd, Howard G, et al: Stenting versus endarterectomy for treatment of carotid-artery stenosis. $N$ Engl J Med 363: 11-23, 2010

3) Chimowitz MI, Poole RM, Starling MR, et al: Frequency and severity of asymptomatic coronary disease in patients of different causes of stroke. Stroke 28: 941-945, 1997

4) Di Pasquale G, Andreoli A, Pinelli G, et al: Cerebral ischemia and asymptomatic coronary artery disease: a prospective study of 83 patients. Stroke 17: 1098-1101, 1986

5) International Carotid Stenting Study investigators, Ederle J, Dobson J, et al: Carotid artery stenting compared with endarterectomy in patients with symptomatic carotid stenosis (International Carotid Stenting Study): an interim analysis of a randomized controlled trial. Lancet 375: 985-997, 2010

6) Illuminati G, Ricco JB, Greco C, et al: Systematic coronary angiography and stenting improves postoperative results of carotid endarterectomy in patients with asymptomatic coronary artery disease: a randomized controlled trial. Eur J Vasc Surg 39: 139-145, 2010

7) Illuminati G, Schneider F, Greco C, et al: Long-term results of a randomized controlled trial analyzing the role of systematic pre-operating coronary angiography before elective carotid endarterectomy in patients with asymptomatic coronary artery disease. Eur J Vasc Endovasc Surg 49: 366-374, 2015
8) Kernan WN, Ovbiagele B, Black HR, et al: Guidelines for the prevention of stroke in patients with stroke and transient ischemic attack: a guideline for healthcare professionals from the American Heart Association/American Stroke Association. Stroke 45: 2160-2236, 2014

9) Kim JG, Lee SJ, Choi H, et al: Silent coronary artery disease in symptomatic candidates for carotid revascularization intervention. Eur Neurol 76: 69-74, 2016

10) Kwon H, Moon DH, Han Y, et al: Impact of subclinical coronary artery disease on the clinical outcomes of carotid endarterectomy. J Neurosurg 126: 1560-1565, 2017

11) Love BB, Grover-McKay M, Biller J, et al: Coronary artery disease and cardiac events with asymptomatic and symptomatic cerebrovascular disease. Stroke 23: 939-945, 1992

12) Mas JL, Trinquart L, Leys D, et al: Endarterectomy versus angioplasty in patients with symptomatic severe carotid stenosis (EVA-3S) trial: results up to 4 years from a randomized, multicenter trial. Lancet Neurol 7: 885-892, 2008

13） 日本脳卒中学会 脳卒中ガイドライン委員会 : 脳卒中ガイド ライン 2015, 東京, 協和企画, 2015, pp127-132, 223-224

14) Noiphthak R, Liengudom A: Recent update on carotid endarterectomy versus carotid artery stenting. Cerebrovasc Dis 43 : 68-75, 2016

15) SPACE collaborative Group, Ringleb PA, Allenberg J, et al: 30 day results from the SPACE trial of stent-protected angioplasty versus carotid endarterectomy in symptomatic patients: a randomized non-inferiority trial. Lancet 368: 12391247,2006

16) Yadav JS, Wholey MH, Kuntz RE, et al: Protected carotid-artery stenting versus endarterectomy in high-risk patients. $N$ Engl J Med 351: 1493-1501, 2004 